\title{
Aplikasi Prediksi Harga Emas dan Administrasi Toko Perhiasan Berbasis PHP dan Scan QR-Code Menggunakan Metode Regresi Linear Sederhana
}

\author{
Sigit Riyadi, Rizki Liantini \\ Manajemen Informatika, STMIK Yadika Bangil \\ email : sigitriyadi@stmik-yadika.ac.id, rizkiliantini321@gmail.com
}

DOI: http://dx.doi.org/10.21107/rekayasa.v12i1.4553

\begin{abstract}
ABSTRAK
Perkembangan zaman pada siklus jual-beli perhiasan saat ini tentunya tidak lepas dari teknologi informasi. Didalam menentukan harga jual-beli perhiasan, aplikasi prediksi harga emas pada toko perhiasan dapat membantu pemilik toko dalam menentukan harga jual ataupun beli perhiasan. Aplikasi prediksi harga emas dan administrasi toko perhiasan berbasis php dan scan gr-code. Metode yang digunakan dalam menentukan prediksi yaitu metode Regresi Linier Sederhana. Perancangan sistemnya menggunakan PHP, database MySql (XAMPP) dan di akses secara offline. Dengan menggunakan aplikasi ini dapat mempermudah kinerja yang lebih efektif dan efisien.
\end{abstract}

Kata Kunci : Aplikasi Prediksi, Administrasi, Toko, Scan QR-Code, Regresi Linier Sederhana

\section{Application of Gold Price Prediction and Administration of Jewelry Shop based on PHP and Scan QR-Code Using Simple Linear Regression Method}

\section{ABSTRACT}

The development of the times in the cycle of buying and selling jewelry at this time certainly cannot be separated from information technology. In determining the purchase price of jewelry, gold price prediction app at jewelry store can help store owner in determining sale price or buy jewelry. Gold price prediction app and PHP jewelry store administration and QR-code scan. The method used in determining the prediction is the Simple Linear Regression method. The design of the system using PHP, MySql database (XAMPP) and in access offline. By using this application can facilitate more effective and efficient performance.

Keywords: Prediction, Administration, Store Application, QR-Code Scan, Simple Linear Regression

\section{PENDAHULUAN}

Toko perhiasan adalah tempat untuk melakukan suatu transaksi jual-beli sebuah benda yang terbuat dari emas yang digunakan untuk merias diri khususnya bagi kaum wanita. Perhiasan emas merupakan jenis perhiasan yang paling sering ditemui dalam kehidupan sehari-hari, misalnya dalam bentuk cincin, kalung, gelang, dan lain-lain. Perhiasan tidak hanya bisa digunakan sebagai koleksi tetapi juga dapat digunakan sebagai media investasi yang baik untuk jangka panjang, karena nilainya cenderung stabil bahkan bisa meningkat dan dapat diterima di wilayah dan negara manapun.

\section{Article History:}

Received: Maret 2019; Accepted: April 2019

ISSN: 2502-5325 (Online) Terakreditasi Peringkat 4 oleh Kementerian Riset, Teknologi dan Pendidikan Tinggi (ARJUNA), berdasarkan Keputusan Direktur Jenderal Penguatan Riset dan Pengembangan Nomor: 21/E/KPT/2018 tanggal 9 Juli 2018
Dalam menentukan harga jual ataupun beli emas, sebuah toko emas setidaknya memiliki sistem prediksi harga emas. Regresi Linear Sederhana ini merupakan metode yang akan digunakan dalam penelitian. Regresi Linear Sederhana juga merupakan salah satu teknik analisis statistika yang digunakan untuk menggambarkan hubungan antara satu variabel respon dengan satu atau lebih variabel penjelas. Hasil nilai keakuratannya menunjukkan bahwa korelasi dari regresi linear sangat bagus, yaitu 0,929. Sehingga jika kita dapat memahami bagaimana pergeseran harga emas maka kita mampu mendapatkan untung.

Toko Perhiasan Emas Sriwijaya di Bangil merupakan toko perhiasan yang ramai dikunjunCite this as:

Riyadi, S., \& Liantini, R. (2019). Aplikasi Prediksi Harga Emas dan Administrasi Toko Perhiasan Berbasis PHP dan Scan QR-Code Menggunakan Metode Regresi Linear Sederhana. Rekayasa, 12(1), 71-74. doi:http://dx.doi.org/10.21107/rekayasa.v12i1.4553 
gi pembeli. Di Toko Perhiasan Emas Sriwijaya menjual berbagai bentuk perhiasan dari emas seperti kalung, gelang, cincin, liontin dan lainlain. Tetapi di Toko Perhiasan Emas Sriwijaya sistem penjualannya masih manual belum terkomputerisasi dengan baik.

Oleh karena itu penulis ingin memberikan alternatif dengan aplikasi prediksi harga emas dan administrasi toko perhiasan berbasis php ini untuk mempermudah pekerjaan agar terkomputerisasi dengan baik, adapun data-datanya meliputi data karyawan, data barang, data kategori, data penjualan, data pembelian, data harga, data reparasi dan data prediksi.

\section{Metode Penelitian}

Pendekatan yang digunakan dalam penelitian ini dibagi dalam beberapa tahapan sebagai berikut :

\section{Observasi}

Dalam metode ini penulis mengadakan pengamatan langsung ke Toko Perhiasan.

\section{Wawancara}

Metode ini dilakukan dengan cara mengadakan tanya jawab dengan pemilik dan karyawan di tempat penulis melakukan penelitian.

\section{Studi Pustaka}

Bentuk pencarian informasi dengan cara mengumpulkan dan mempelajari berbagai literature, buku referensi maupun sumber dari internet yang berkaitan dengan program aplikasi yang akan dibuat.

\section{Perancangan Sistem}

Pada tahapan ini yang dilakukan adalah perancangan sistem yaitu membuat Diagram Context, Data Flow Diagram, Flowchart, dan Desain Form, untuk membuat aplikasi yang di inginkan oleh Pemilik Toko. Perancangan sistem adalah sekumpulan aktivitas yang menggambarkan secara rinci bagai mana sistem akan berjalan. Hal itu bertujuan untuk menghasilkan produk perangkat lunak yang sesuai dengan kebutuhan user. Perancangan sistem dapat dirancang dalam bentuk bagan alir sistem ( sistem flowchart ), yang merupakan alat bentuk grafik yang dapat digunakan untuk menunjukkan urutan - urutan proses dari sistem.

$\begin{array}{lcr}\text { Diagaram } & \text { Alir (DFD) } & \text { Diagram alir dib- } \\ \text { utuhkan } & \text { untuk } & \text { menggambarkan } \\ \text { sistem } & \text { yang } & \text { dipresentasikan }\end{array}$ sistem yang dipresentasikan hubungkan proses secara fungsional. prosesproses tersebut dihubungan oleh aliran data. dalam diagram alir terdapat entitas, aliran data proses dan data store.

\section{Diagram Konteks}

Diagram konteks yang digunakan pada Aplikasi Toko Perhiasan(Gambar 1).

Diagram Konteks terdapat satu proses pusat berkumpulnya data yang didapat dari 2 entitas terlibat langsung dalam sistem yaitu Admin dan Karyawan

\section{Flowchart}

Flowchart merupakan diagram aliryang menggambarkan urutan logika dari suatu prosedur pemecahan masalah. Gambar 2 adalah Flowchart Admin yang dimulai dengan login pilih menu yang akan dibuka, jika memilih menu prediksi, admin dapat update data prediksi yang ada dan bisa mengakses menu lainnya.

Flowchart menggambarkan alur proses Menu Utama Admin dimulai dari login hingga menampilkan data dari Data Barang, Data Harga, Data Kategori, Data Karyawan, Data Inflasi, Data Penjualan, Data Pembelian Data Regresi, Data Reparasi dan Logout.

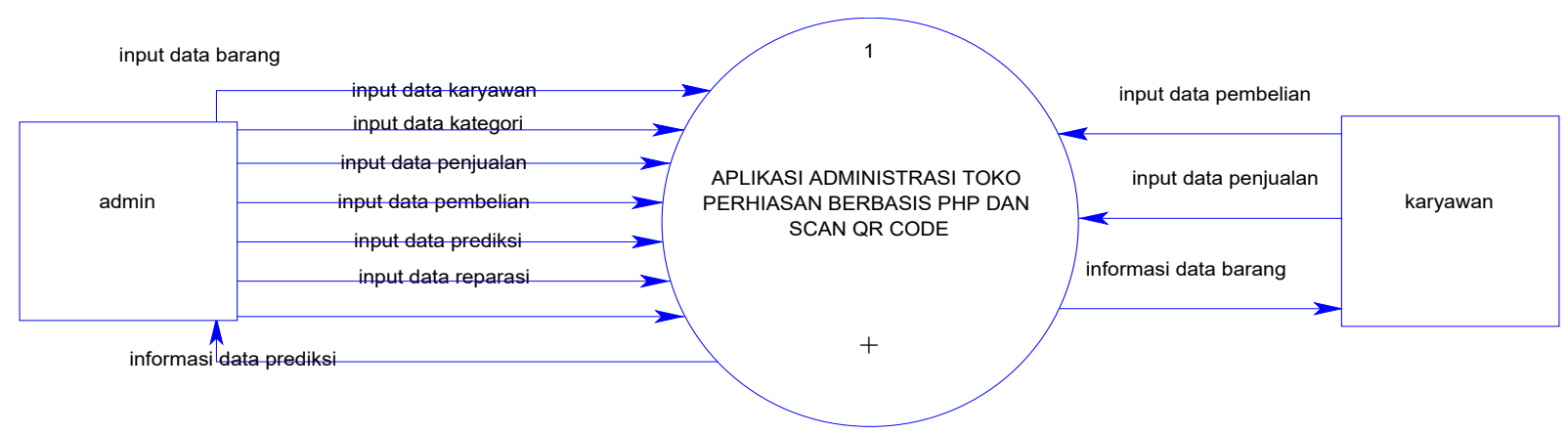

Gambar 1. Diagram Konteks Sistem Toko Perhiasan 


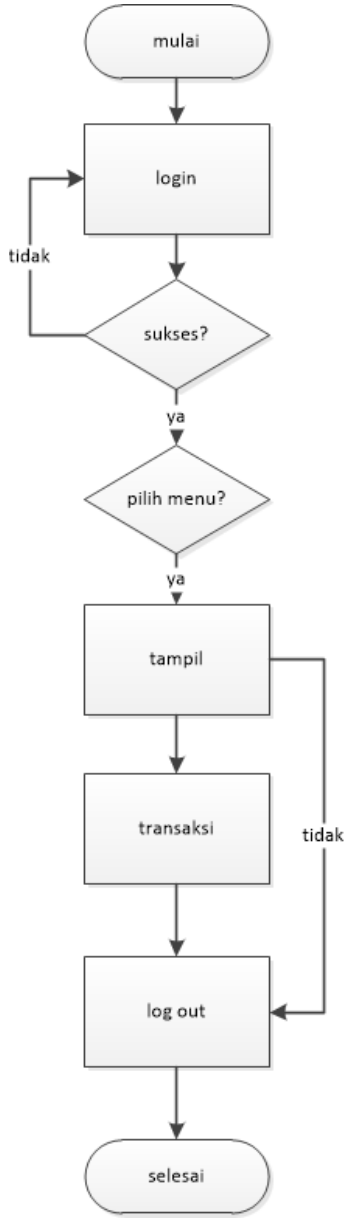

Gambar 2. Flowchart

\section{HASIL DAN PEMBAHASAN}

Aplikasi prediksi harga emas dan administrasi toko perhiasan berbasis php dan Scan QR - Code menggunakan metode regresi Linear sederhana ini dibuat dengan menggunakan bahasa pemrograman PHP (hypertext processor). Penulis menggunakan bahasa pemrograman ini karena penulis merasa mudah untuk dipahami dan desain lebih teratur. Sedangkan untuk desain tampilan dan gambar dari aplikasi ini menggunakan Dreamweaver. Aplikasi ini dapat diakses dari PC, Smartphone, Mac dan Linux karena berbasis web. Sebelum aplikasi ini digunakan terlebih dahulu aplikasi ini melalui tahap pengujian dan tahapan tersebut hanya melalui koneksi jaringan Wiifi atau LAN.

Admin yang dapat mengakses halaman inflasi, dimana terdapat tombol simpan untuk menginputkan data inflasi dan harga saat ini kemudian disimpan pada tabel prediksi.

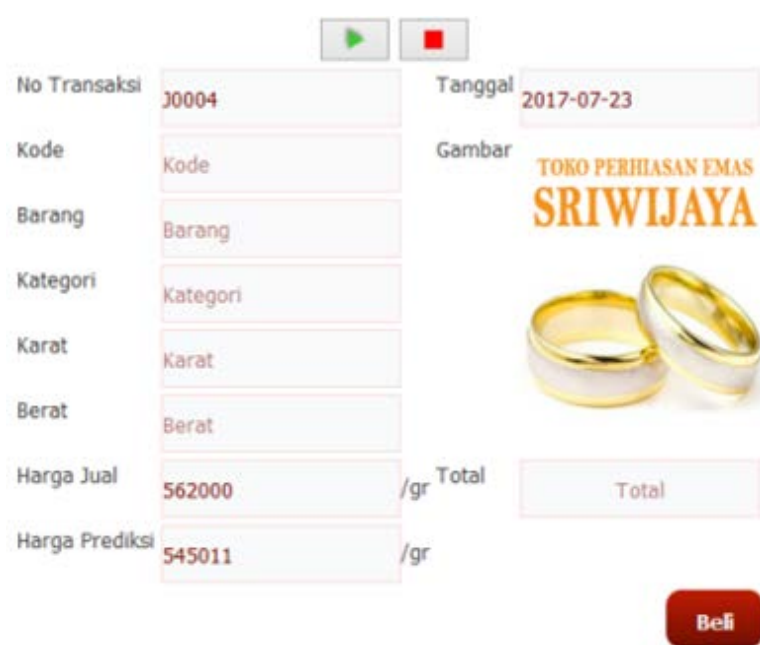

Gambar 3. Menu detail barang yang dijual

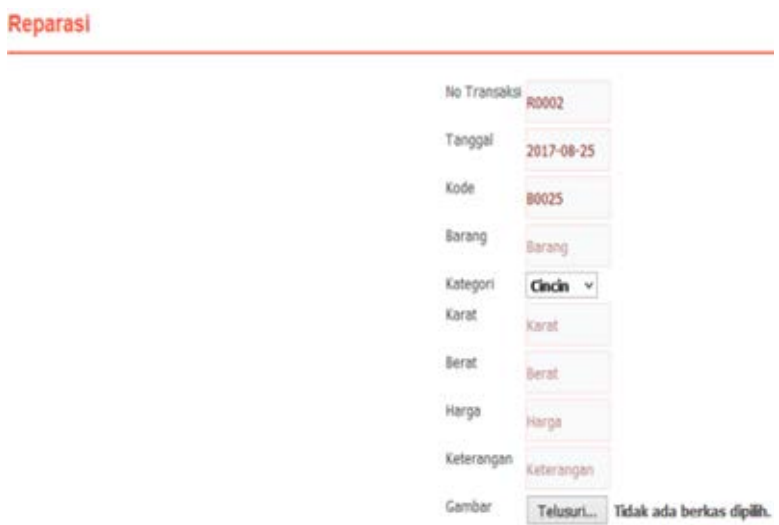

shipan

Gambar 4. Menu Transaksi Reparasi

Pembelian dapat diakses oleh admin. Dan admin dapat menambah dan mengedit data pembelian dalam menu ini. Sehingga dapat memasukkan data penjualan setiap harinya. Pada menu ini memberikan informasi tentang detail barang yang dijual (Gambar 3)

Gambar 4 merupakan tampilan pada menu reparasi. Menu ini dapat di akses oleh admin saat melakukan transaksi reparasi

Dalam pengujian sistem, penulis menggunakan metode Black Box. Diharapkan setiap komponen pada sistem dapat dipastikan berjalan dengan baik.

Metode Black Box bekerja dengan menitik beratkan pada persyaratan atau kebutuhan fungsional pada sistem perangkat lunak yang telah dibuat. pengujian metode Black Box memungkinkan untuk membentuk himpunan kondisi input dan menguji syarat-syarat fungsional program secara keseluruhan. sehingga den- 
gan pengujian tersebut dapat ditemukan kesalahan-kesalahan yang ada pada sistem. Pengujian Black Box berusaha menemukan kesalahan dalam beberapa hal yaitu:

- Fungsi-fungsi yang tidak benar atau salah

- Kesalahan interface

- Kesalahan dalam struktur data atau akses database eksternal

- Kesalahan kinerja, inisialisasi, dan kesalahan terminas

\section{SIMPULAN DAN REKOMENDASI}

Berdasarkan penelitian yang dilakukan pada bab - bab sebelumnya dalam penelitian ini, maka dapat diambil kesimpulan beberapa hal sebagai berikut :

- Aplikasi prediksi harga emas dan administrasi toko perhiasan berbasis php dan scan qr-code menggunakan metode regresi linear sederhana dapat diakses menggunakan PC Desktop, Laptop, dan Smartphone.

- Metode regresi linear sederhana dapat memprediksi harga emas dengan nilai galat yang sangat tinggi yaitu sebesar 587004, sedangkan data nilai sebenarnya untuk tanggal 09 agustus 2017 adalah sebesar 587034,48. artinya nilai galat yang sangat tinggi tergantung dengan variabel pembanding yaitu harga galat dengan inflasi.

Pada bagian akhir dari penyusunan penelitian ini, penulis menyadari segala kekurangan dan keterbatasan yang dimiliki dalam penulisan penelitian ini, maka dari itu saran-saran yang dapat dikemukakan adalah sebagai berikut:

- Program dan penelitian yang telah dikerjakan oleh penulis ini hendaknya dan berharap adanya pengembangan yang signifikan.

- Memelihara aplikasi yang dibangun guna menjaga kesalahan pada source code.

- Sekiranya aplikasi ini dapat diakses online jika sudah tersebar umum agar semua dapat satu akses program yang sama.

\section{DAFTAR PUSTAKA}

Model Geographically Weighted Regression (GWR) Dengan Statistik Uji F dan Uji T. Malang.

Christina, Chintya. 2012. Prediksi Harga Emas Menggunakan Metode Neuro-Fuzzy Tipe 2. Telkom University, Bandung.

Hengky W. Pramana. 2006. Aplikasi Inventory Berbasis Access 2003, Elex Media Komputindo, Jakarta.

Indrajani,S.Kom.,MM. 2015. Database Design. PT. Elex Komputindo. Jakarta

Raharjo, Budi. 2011. Belajar Otodidak Pemrograman Web dengan PHP + Orcacle Informatika Bandung, Bandung.

R Sanjaya, OW Purbo. 2001. Membuat aplikasi WAP dengan PHP. Jakarta: Elex Media Komputindo.

Riyadi, Sigit, and Siska Angraeni. "Sistem Informasi Monitoring Prestasi Akademik Di Sdn Gadingrejo I Berbasis Web." Jurnal SPIRIT 8.1 (2016).

Sugiyono. 2013. Statistika untuk Penelitian. Bandung: Alfabeta

Sungkawa, Iwa. 2013. Penerapan Analisis Regresi Dan Korelasi Dalam Menentukan Arah Hubungan Antara Dua Faktor Kualitatif Pada Tabel Kontingensi. Jakarta Barat.

Sutrisno, Hadi. 2007. Analisis Regresi.Yogyakarta: Andi Ofset.

Suwarno Bambang. 2007. Rumus dan Data dalam Analisis Statistika. Bandung: ALFABETA. 